http://doi.org/10.35784/iapgos.2578

\title{
APPLICATION OF THE MATRIX FACTOR ANALYSIS METHOD FOR DETERMINING PARAMETERS OF THE OBJECTIVE FUNCTION FOR TRANSPORT RISK MINIMIZATION
}

\author{
Serhii Zabolotnii ${ }^{1}$, Sergii Mogilei ${ }^{2}$ \\ ${ }^{1}$ Cherkasy State Business-College, Cherkasy, Ukraine, ${ }^{2}$ Rauf Ablyazov East European University, Cherkasy, Ukraine
}

Abstract. The paper regards a common transport problem with a non-classic optimization criterion to minimize transportation risks. It demonstrates that the risk parameters of the function could be found through the factor analysis method. Besides, considering that the problem contains several points of sending and delivering loads, the method is dealt with as a matrix. The research also regards the algorithm of matrix factor analysis application for determining parameters of the objective function for the problem to be solved. The survey results in a new method to construct the objective function for the optimization problem with probability parameters. It generally assists in suggesting a formal solution to such problems, foremost due to particular software.

Keywords: factor analysis, objective function of optimization, transportation risk

\section{ZASTOSOWANIE METODY ANALIZY WSPÓLCZYNNIKA MACIERZOWEGO DO OKREŚLENIA PARAMETRÓW FUNKCJI CELU DLA MINIMALIZACJI RYZYKA W TRANSPORCIE}

Streszczenie. Artykut dotyczy powszechnego problemu transportowego z nieklasycznym kryterium optymalizacji w celu zminimalizowania ryzyka transportowego. Wykazano, że parametry ryzyka takiej funkcji można wyznaczyć metoda analizy czynnikowej. Dodatkowo, ze względu na wystęowanie $w$ zgłoszeniu problemu kilku punktów wysytki i dostawy towarów, metoda ta jest prezentowana w postaci matrycy. W wyniku przeprowadzonych badań uzyskano nowa metodę konstruowania funkcji celu dla postawionego problemu optymalizacji, której parametry maja charakter probabilistyczny. Pozwala to na ogólne sformalizowanie procesu rozwiązywania tego typu problemów - przede wszystkim przy pomocy specjalistycznego oprogramowania.

Słowa kluczowe: analiza czynnikowa, funkcja optymalizacji celu, ryzyko transportowe

\section{Introduction}

Problem of minimizing transportation risks is raised quite dramatically amidst more and more intensive world economy globalization. Country borders have already become formally distinct and the whole world is getting more available to its population. In this aspect, long distance transportation becomes a norm. Although, the longer distance goods are delivered, the bigger is risk of their getting spoiled, damaged or completely ruined.

Taking all propositions into consideration, it seems quite correct to join the effort of all interested experts to investigate concrete issues of risk factors appearance and their elimination during transportations. Hence, it is important to make a quantitative calculation for the risk level, in both general and separately regarded values that are constituents of the aggregated ones. The calculations of the kind can form a solid basis for taking complex logistics solutions as for the time and means of departure, as well as of means of deliverance.

Considering contemporary experience in solving such problems, it should be mentioned that their solution is to be based on the so called transportation problem. Hence, it must be regarded in detail.

Classic (standard) transportation problem lies in determining an optimal plan for transport logistics when some load $x_{i j}$ is to be delivered from $m$ departure points to $n$ points of delivery. The actual criterion of optimization is objective function $S$ for minimizing the transportation costs [3]. Thus:

$$
S=\sum_{i, j=1}^{m, n} c_{i j} x_{i j} \rightarrow \min
$$

where by $c_{i j}$ we mark transportation cost between $i$ and $j$, stating that $i=\overline{1, m} ; j=\overline{1, n}$.

Problem like (1) appears to be explored enough [7], but, in case it is differently revealed, its solution could be quite specific. For example, instead of objective function for minimizing costs there might be offered criterion $R$, to minimize transportation risks [9]. Thus, the problem is as follows:

$$
R=\sum_{i, j=1}^{m, n} r_{i j} x_{i j} \rightarrow \min
$$

where by $r_{i j}$ the level of transportation risk is shown for points $i$ and $j$.
Obviously, problems (1) and (2) seem to be similar, though there is a great difference between coefficients $c_{i j}$ and $r_{i j}$. Indeed, parameters $c_{i j}$ of cost function are calculated in money units and are concrete enough, whereas parameters $r_{i j}$ of risk function appear to be probability rendered risk events. In addition, the latter are as well aggregated risk markers and require further analysis.

Generally, there emerges a problem of constructing objective functions of optimization with probability parameters. Thus, in the aspect of optimization theory, to find a solution for the optimization problem a mere general target function is needed, or a certain analytical expression with variables and parameters. However, this theory never gives solution to calculating such parameters, and so, there are "auxiliary" scientific studies that matter, which could apply a more distinct description to methods and algorithms in finding the parameters for optimization function. It is important to mention that such methods and algorithms are distinctly correlated with essential peculiarities of objective functions, though, there exists, to some extent, a possibility to describe and apply quite universal approaches to solving this problem.

Thus, if problem (1) contains "cost as a parameter", then problem (2) suggests "probability as a parameter", and the research is fully concentrated on probability parameters. That means the research is aimed at describing universal approach to calculating probability parameters of the related objective function. The description is fully based on objective function of minimization as in (2).

Foremost, to calculate the aggregated risk indices (parameters) it is necessary to decompose them according to constituents. That means, risk factors must be found which affect the value of aggregated index. That enables to apply factor analysis method to solving problem (2) [1].

There are quite many instances of risk factors marked by $v$, whereas each factor is marked by $k$ index, where $k=\overline{1, v}$. Here are three following factors $(v=3)$ : emergency $(k=1)$, transport vehicle breakdown $(k=2)$ and force majeur circumstances $(k=3)$. Besides, effect (importance) of each factor on the value of aggregated index $r_{i j}$ might differ. Considering that, marker $w^{k}$ is introduced which is weight coefficient of $k$-factor effect. In addition, factor coefficients are normalized:

$$
\sum_{k=1}^{v} w^{k}=1 ; w^{k}>0
$$


Condition (3) would be put differently considering that values of $w^{k}$ coefficients differ as they depend on from which departure point $i$ the load is transported to delivery point $j$. Thus, weight coefficients of influence are marked by $\left(w^{k}\right)_{i j}$. Further it will be demonstrated that in stating parameters of problem (2) they must be given in matrix, so the method proper is named as matrix factor analysis.

As for calculating concrete values for coefficient (3) a number of methods can be applied here, particularly the experts' method (method of expert estimates, or Delphi's method). It lies in analyzing approaches of prominent experts working in relevant fields [2].

On the other hand, another perspective method for investigating the problem can be group factor analysis $[8,10]$. Its application is possible due to building up the hierarchy of influence factors; however, within the problem solution it is not to be applied as the solution requires only single hierarchy level. Besides, to achieve a required level of presentation, the problem should contain a larger number of risk factors.

\section{The research problem statement and solution method}

Thus, the research problem lies in finding parameters of objective function (2). To solve this problem, the approach suggested in [6] must be applied. The following proportion means:

$$
r_{i j}=\sum_{k=1}^{v}\left(a^{k}\right)_{i j} \times\left(w^{k}\right)_{i j}+o_{i j}
$$

where index of risk level of $k$ factor is marked by $a^{k}$, and $\mathrm{o}_{i j}$ is the "gaussian noise", the value of which within the research problem may be neglected.

Generally, the matter of neglecting "gaussian noise" remains under consideration. Actually, the more complete is the number $v$ of risk factors of transportation, the smaller this value would be.

It must be admitted, the $\left(a^{k}\right)_{i j}$ coefficients are as well probable for certain risk events to occur. However, in contrast with $r_{i j}$, they are not aggregated indices therefore it is possible to calculate their value based on results of real observations assisted by familiar methods of mathematical statistics [4].

Furthermore, sense of proportion given in expression (4) must be specified. Suppose, there are $m=2$ points of departure and $n=3$ delivery points. Then, for instance, for $k=1$ the equation is:

$$
\left(a^{1}\right)_{i j}=\left(\begin{array}{lll}
a_{11}^{1} & a_{12}^{1} & a_{13}^{1} \\
a_{21}^{1} & a_{22}^{1} & a_{23}^{1}
\end{array}\right)
$$

In case, when weights $\left(w^{k}\right)_{i j}$ are given in simplified form $w^{k}$, first item in proportion (4) is a common multiplication of coefficients of matrix (5) by $w^{l}$. In the opposite case, there may be a certain relation between two matrices. With $k=1$ the coefficient matrix $\left(w^{k}\right)_{i j}$ appears to be:

$$
\left(w^{1}\right)_{i j}=\left(\begin{array}{lll}
w_{11}^{1} & w_{12}^{1} & w_{13}^{1} \\
w_{21}^{1} & w_{22}^{1} & w_{23}^{1}
\end{array}\right)
$$

That means the relation in (4) for expressions (5) and (6) is revealed as follows:

$$
\left(a^{1}\right)_{i j} \times\left(w^{1}\right)_{i j}=\left(\begin{array}{ccc}
a_{11}^{1} \cdot w_{11}^{1} & a_{12}^{1} \cdot w_{12}^{1} & a_{13}^{1} \cdot w_{13}^{1} \\
a_{21}^{1} \cdot w_{21}^{1} & a_{22}^{1} \cdot w_{22}^{1} & a_{23}^{1} \cdot w_{23}^{1}
\end{array}\right)
$$

With $k=2$ and $k=3$ the expressions (5) - (7) are put similarly.

For ultimate value of aggregated risk indices $r_{i j}$, the formula for their calculation is put for $r_{11}$ :

$$
r_{11}=a_{11}^{1} \cdot w_{11}^{1}+a_{11}^{2} \cdot w_{11}^{2}+a_{11}^{3} \cdot w_{11}^{3}
$$

It means, to calculate parameters of objective function (2), relation (7) was additionally introduced. Therefore, the question arises if it is possible to do without introducing any of such specific relations and confine to common mathematical approaches.

It is easily noticed that in (8) $r_{11}$ is the result of scalar multiplication of following vectors:

$$
r_{11}=\left(a_{11}^{1} ; a_{11}^{2} ; a_{11}^{3}\right) \cdot\left(w_{11}^{1} ; w_{11}^{2} ; w_{11}^{3}\right)=\left(\begin{array}{lll}
a_{11}^{1} & a_{11}^{2} & a_{11}^{3}
\end{array}\right) \cdot\left(\begin{array}{l}
w_{11}^{1} \\
w_{11}^{2} \\
w_{11}^{3}
\end{array}\right)
$$

Expression (9) is put simultaneously for $r_{11}$ and $r_{21}$ :

$$
\left(\begin{array}{cc}
r_{11} & 0 \\
0 & r_{21}
\end{array}\right)=\left(\begin{array}{lll}
a_{11}^{1} & a_{11}^{2} & a_{11}^{3} \\
a_{21}^{1} & a_{21}^{2} & a_{21}^{3}
\end{array}\right) \cdot\left(\begin{array}{ll}
w_{11}^{1} & w_{21}^{1} \\
w_{11}^{2} & w_{21}^{2} \\
w_{11}^{3} & w_{21}^{3}
\end{array}\right)
$$

Expression (10) occurs only if in case of unequal upper and lower indices in parameters $\left(w^{k}\right)_{i j}$ and $\left(a^{k}\right)_{i j}$ their multiplication is 0 . This condition is to be named the equality of indices. It must be assumed that to check this condition without proper software is quite cumbersome. Therefore, it seems obvious to better solve it applying specific program instruments.

The indices being equal, expression (10) can be extended for all aggregated parameters $r_{i j}$ :

$$
\left(\begin{array}{ccc}
\ldots & 0 & 0 \\
0 & r_{i j} & 0 \\
0 & 0 & \ldots
\end{array}\right)=\left(\begin{array}{cccc} 
& \ldots & \\
a_{i j}^{1} & a_{i j}^{2} & \ldots & a_{i j}^{v} \\
& \ldots &
\end{array}\right) \cdot\left(\begin{array}{ccc} 
& w_{i j}^{1} & \\
& w_{i j}^{2} & \\
\ldots & \ldots \\
& w_{i j}^{v} &
\end{array}\right)
$$

Or, if to make matrix transposition $\left(w^{k}\right)_{i j}$ like (6):

$$
\left(\begin{array}{ccc}
\ldots & 0 & 0 \\
0 & r_{i j} & 0 \\
0 & 0 & \ldots
\end{array}\right)=\left(\begin{array}{cccc} 
& \ldots & & \\
a_{i j}^{1} & a_{i j}^{2} & \ldots & a_{i j}^{v} \\
& \ldots &
\end{array}\right) \cdot\left(\begin{array}{cccc} 
& \ldots & & \\
w_{i j}^{1} & w_{i j}^{2} & \ldots & w_{i j}^{v} \\
& \ldots & &
\end{array}\right)^{T}
$$

Then, relation (4) may be put as:

$$
\left(r_{i j}\right)=\sum_{k=1}^{v}\left(a^{k}\right)_{i j} \times\left(w^{k}\right)_{i j}=\left(a^{k}\right)_{i j} \cdot\left(w^{k}\right)_{i j}^{T}
$$

where by $\left(r_{i j}\right)$ diagonal matrix with elements $r_{i j}$ of main diagonal is marked.

Thus, in case parameters of objective function are calculated as probability for certain events to occur or not, it is necessary to state the factors that affect the value of these probabilities. That would enable to calculate the given parameters with the above mentioned approach.

It is to be admitted, in case the mentioned risk factors are regarded as certain aggregated values thus implying there is another level of influence factors hierarchy that enables to apply group factor analysis method to solve the issues of the problem given. In fact, that would mean another (11) - (13) iteration to calculate $\left(a^{k}\right)_{i j}$ coefficients. Hence, in the aspect of program solution of the problem, its solving in this case is never complicated, as all key procedures and functions are to be preliminarily taken into consideration.

The example of the research problem solution is given further with model data.

\section{The research problem solution for model instance}

Supposing that problem (2) contains $m=2$ and $n=3$, concrete values for (10) are:

$$
\left(\begin{array}{cc}
r_{11} & 0 \\
0 & r_{21}
\end{array}\right)=\left(\begin{array}{ccc}
0.1 & 0.15 & 0.12 \\
0.2 & 0.22 & 0.16
\end{array}\right) \cdot\left(\begin{array}{cc}
0.5 & 0.4 \\
0.4 & 0.3 \\
0.1 & 0.3
\end{array}\right)
$$

It should be mentioned, that condition (3) for $\left(w^{k}\right)_{i j}$ being definitely completed. Further values are put similarly:

$$
\left(\begin{array}{cc}
r_{12} & 0 \\
0 & r_{22}
\end{array}\right)=\left(\begin{array}{ccc}
0.3 & 0.17 & 0.05 \\
0.1 & 0.19 & 0.24
\end{array}\right) \cdot\left(\begin{array}{cc}
0.3 & 0.2 \\
0.5 & 0.7 \\
0.2 & 0.1
\end{array}\right)
$$




$$
\left(\begin{array}{cc}
r_{13} & 0 \\
0 & r_{23}
\end{array}\right)=\left(\begin{array}{ccc}
0.2 & 0.22 & 0.11 \\
0.13 & 0.26 & 0.18
\end{array}\right) \cdot\left(\begin{array}{cc}
0.7 & 0.8 \\
0.1 & 0.1 \\
0.2 & 0.1
\end{array}\right)
$$

For program completion of the problem, expressions (14) (16) can be joined into a single data array and processed by regulation (12). The condition of the indices equality being as well considered

Hence,

$$
\left(\begin{array}{cccccc}
r_{11} & 0 & 0 & 0 & 0 & 0 \\
0 & r_{21} & 0 & 0 & 0 & 0 \\
0 & 0 & r_{12} & 0 & 0 & 0 \\
0 & 0 & 0 & r_{22} & 0 & 0 \\
0 & 0 & 0 & 0 & r_{13} & 0 \\
0 & 0 & 0 & 0 & 0 & r_{23}
\end{array}\right)=
$$

$$
=\left(\begin{array}{ccc}
0.1 & 0.15 & 0.12 \\
0.2 & 0.22 & 0.16 \\
0.3 & 0.17 & 0.05 \\
0.1 & 0.19 & 0.24 \\
0.2 & 0.22 & 0.11 \\
0.13 & 0.26 & 0.18
\end{array}\right) \cdot\left(\begin{array}{cccccc}
0.5 & 0.4 & 0.3 & 0.2 & 0.7 & 0.8 \\
0.4 & 0.3 & 0.5 & 0.7 & 0.1 & 0.1 \\
0.1 & 0.3 & 0.2 & 0.1 & 0.2 & 0.1
\end{array}\right)
$$

The simple calculations would result in:

$\left(\begin{array}{cc}r_{11} & 0 \\ 0 & r_{21}\end{array}\right)=$

$$
\begin{aligned}
& =\left(\begin{array}{cc}
0.1 \cdot 0.5+0.15 \cdot 0.4+0.12 \cdot 0.1 & 0 \\
0 & 0.2 \cdot 0.4+0.22 \cdot 0.3+0.16 \cdot 03
\end{array}\right)= \\
& =\left(\begin{array}{cc}
0.05+0.06+0.012 & 0 \\
0 & 0.08+0.066+0.048
\end{array}\right) \\
& \left(\begin{array}{cc}
r_{12} & 0 \\
0 & r_{22}
\end{array}\right)= \\
& =\left(\begin{array}{cc}
0.3 \cdot 0.3+0.17 \cdot 0.5+0.05 \cdot 0.2 & 0.1 \cdot 0.2+0.19 \cdot 0.7+0.24 \cdot 0.1
\end{array}\right)= \\
& =\left(\begin{array}{cc}
0.09+0.085+0.01 & 0 \\
0 & 0.02+0.133+0.024
\end{array}\right) \\
& \left(\begin{array}{cc}
r_{13} & 0 \\
0 & r_{23}
\end{array}\right)=\begin{array}{c}
0 \\
0.2 \cdot 0.7+0.22 \cdot 0.1+0.11 \cdot 0.2
\end{array} \\
& =\left(\begin{array}{cc}
0 & 0.13 \cdot 0.8+0.26 \cdot 0.1+0.18 \cdot 0.1
\end{array}\right)= \\
& =\left(\begin{array}{cc}
0.14+0.022+0.022 & 0 \\
0 & 0.104+0.026+0.018
\end{array}\right) \\
& \text { Ultimately, }
\end{aligned}
$$

$$
\begin{aligned}
& \left(\begin{array}{cc}
r_{11} & 0 \\
0 & r_{21}
\end{array}\right)=\left(\begin{array}{cc}
0.122 & 0 \\
0 & 0.194
\end{array}\right) \\
& \left(\begin{array}{cc}
r_{12} & 0 \\
0 & r_{22}
\end{array}\right)=\left(\begin{array}{cc}
0.185 & 0 \\
0 & 0.177
\end{array}\right) \\
& \left(\begin{array}{cc}
r_{13} & 0 \\
0 & r_{23}
\end{array}\right)=\left(\begin{array}{cc}
0.184 & 0 \\
0 & 0.148
\end{array}\right)
\end{aligned}
$$

or as (17):

$$
\left(\begin{array}{cccccc}
r_{11} & 0 & 0 & 0 & 0 & 0 \\
0 & r_{21} & 0 & 0 & 0 & 0 \\
0 & 0 & r_{12} & 0 & 0 & 0 \\
0 & 0 & 0 & r_{22} & 0 & 0 \\
0 & 0 & 0 & 0 & r_{13} & 0 \\
0 & 0 & 0 & 0 & 0 & r_{23}
\end{array}\right)=
$$

$$
=\left(\begin{array}{cccccc}
0.122 & 0 & 0 & 0 & 0 & 0 \\
0 & 0.194 & 0 & 0 & 0 & 0 \\
0 & 0 & 0.185 & 0 & 0 & 0 \\
0 & 0 & 0 & 0.177 & 0 & 0 \\
0 & 0 & 0 & 0 & 0.184 & 0 \\
0 & 0 & 0 & 0 & 0 & 0.148
\end{array}\right)
$$

Results (18) - (20) are checked by MS Excel. Table 1 contains values of $\left(a^{k}\right)_{i j}$ coefficients.

Table 1. Indices of risk level for each factor

\begin{tabular}{|c|c|c|}
\hline$\left(a^{l}\right)_{i j}$ & $\left(a^{2}\right)_{i j}$ & $\left(a^{3}\right)_{i j}$ \\
\hline 0.1 & 0.15 & 0.12 \\
\hline 0.2 & 0.22 & 0.16 \\
\hline 0.3 & 0.17 & 0.05 \\
\hline 0.1 & 0.19 & 0.24 \\
\hline 0.2 & 0.22 & 0.11 \\
\hline 0.13 & 0.26 & 0.18 \\
\hline
\end{tabular}

Table 2 contains values of $\left(w^{k}\right)_{i j}$ coefficients.

Table 2. Indices of weight for risk factors

\begin{tabular}{|c|c|c|}
\hline$\left(w^{I}\right)_{i j}$ & $\left(w^{2}\right)_{i j}$ & $\left(w^{3}\right)_{i j}$ \\
\hline 0.5 & 0.4 & 0.1 \\
\hline 0.4 & 0.3 & 0.3 \\
\hline 0.3 & 0.5 & 0.2 \\
\hline 0.2 & 0.7 & 0.1 \\
\hline 0.7 & 0.1 & 0.2 \\
\hline 0.8 & 0.1 & 0.1 \\
\hline
\end{tabular}

Results of calculations are shown in Figure 1.

\begin{tabular}{|l|l|l|l|l|l|}
\hline 0.122 & 0.000 & 0.000 & 0.00 & 0.00 & 0.00 \\
\hline 0.000 & 0.194 & 0.000 & 0.00 & 0.00 & 0.00 \\
\hline 0.000 & 0.000 & 0.185 & 0.000 & 0.000 & 0.000 \\
\hline 0.000 & 0.000 & 0.000 & 0.177 & 0.000 & 0.000 \\
\hline 0.000 & 0.000 & 0.000 & 0.000 & 0.184 & 0.000 \\
\hline 0.000 & 0.000 & 0.000 & 0.000 & 0.000 & 0.148 \\
\hline
\end{tabular}

Fig. 1. Results of calculations by MS Excel

It must be admitted, MS Excel is not at all the only program mathematical means by which the solution is possible, other specialized instruments alike being Mathcad and Matlab [5]. However, it is clear that the condition of indices equality can't be checked by those program means. The ultimate result of problem solution is given as a row vector:

$$
\left(r_{i j}\right)=(0.122 ; 0.194 ; 0.185 ; 0.177 ; 0.184 ; 0.148) \text {. }
$$

Obviously, results of handmade calculations coincide with those obtained by applied software. A more distinct computer solution of the problem could be performed by open code programs, through the condition of indices equality check. 


\section{Conclusions}

The paper regards classical transport problem which presupposes calculation of optimal plan of transportations from several departure points to several points of delivery. Instead of criterion of minimal transportation cost as objective function, minimization of their risk level is taken. Values of parameters for risk function of optimization appear to have a sense of probability. To calculate them, method of factor analysis is applied as a matrix that is matrix factor analysis.

Model example demonstrates the work of the method, the calculations of objective function parameters being made both by hand and by MS Excel. The results of problem solution are shown to be quite similar for both cases.

In further studies, the matrix factor analysis method may be applied for solving other problems alike. It could be also regarded as algorithm basis for solving similar problems through specific software.

Another scientific interest is to be presented by similar studies in context of multimodal and intermodal transportations. The transportation problem in this case would involve far more numerous risk factors that may permit to present a more distinct perspective of the above mentioned method for creating its objective function. In addition, solving multi criteria transportation problems would permit to find further "interaction" in several different optimization criteria both probable and nonprobable. As for the program solution of the problem, the above mentioned cases are hardly able to provide for ready program products in order to solve this task. Therefore, it would be necessary to apply the open-code software.

\section{References}

[1] Boyd K. C.: Factor analysis. In The Routledge Handbook of Research Methods in the Study of Religion. Taylor and Francis, 2013, 204-216 [http://doi.org/10.4324/9780203154281-22].

[2] Chalmers J., Armour M.: The Delphi technique. In Handbook of Research Methods in Health Social Sciences. Springer, Singapore 2019, 715-735 [http://doi.org/10.1007/978-981-10-5251-4_99].

[3] Díaz-Parra O., Ruiz-Vanoye J. A., Bernábe Loranca B, Fuentes-Penna A Barrera-Cámara R.A.: A survey of transportation problems. Journal of Applied Mathematics. Hindawi Publishing Corporation 2014, 848129 [http://doi.org/10.1155/2014/848129].
[4] Freund R. J., Wilson W. J., Mohr D. L.: Data and Statistics. In Statistical Methods, 2010, 1-65 [http://doi.org/10.1016/b978-0-12-374970-3.00001-9].

[5] Honcharov A., Mogilei S.: Solving multimodal transportation problems by different program means. Bulletin of Cherkasy State Technological University 3/2020, 67-74

[6] Klami A., Virtanen S., Leppaaho E., Kaski S.: Group Factor Analysis. IEEE Transactions on Neural Networks and Learning Systems 26(9)/2015, 2136-2147 [http://doi.org/10.1109/TNNLS.2014.2376974]

[7] Privarova R.: Operational analysis tools in solving transport task. Perner's contacts XI(2)/2016, 82-89.

[8] Virtanen S., Klami A., Khan S. A., Kaski, S.: Bayesian group factor analysis Proceedings of the 15th AISTATS, JMLR W\&CP 22/2012, 1269-1277.

[9] Zabolotnii S., Mogilei S.: The methods for determining the parameters of the objective function of multimodal transportation risk. Proceedings of $\mathrm{V}$ International Scientific-Practical Conference "ITEST-2020", Cherkasy 2020, 114-115.

[10] Zhao S., Gao C., Mukherjee S., Engelhardt B. E.: Bayesian group factor analysis with structured sparsity. Journal of Machine Learning Research 17/2016, 1-47.

\section{D.Sc. Serhii Zabolotnii \\ e-mail: zabolotniua@gmail.com}

Serhii Zabolotnii was born in 1973 in Cherkasy, Ukraine. In 1995 he graduated the Department of informational technologies of Cherkasy State Technological University. Doctor of Technical Sciences (2015).

Job: professor of the Department of Computer Engineering and Informational Technologies in Cherkasy State Business-College. Scientific interests: statistical data processing, computer modeling.

Author/co-author of more than 150 publications,

1 monography and 7 patents.

http://orcid.org/0000-0003-0242-2234

\section{M.Sc. Sergii Mogilei}

e-mail: sergiymogiley@gmail.com

Sergii Mogilei is a Ph.D. student in Cherkasy State Technological University and works as a tutor in Rauf Ablyazov East European University (Cherkasy, Ukraine). His main scientific interests include mathematical and computer modeling, business analysis, mathematical programming, decision making theory and logistics.

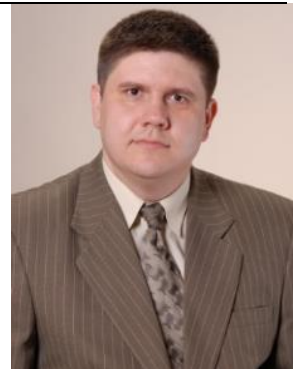

otrzymano/received: 28.02 .2021 przyjęto do druku/accepted: 15.03 .2021 